•研究报告・

\title{
农田节肢动物不同取样方法的综合比较
}

段美春 ${ }^{1}$, 覃如霞 ${ }^{1}$, 张宏斌 ${ }^{2}$, 陈宝雄 ${ }^{*}$, 金樹 ${ }^{3}, 弓$ 松泊 ${ }^{3}$, 任少鹏 ${ }^{4}$, 金树权 $^{4}$, 朱升 海 $^{5}$, 华家宁 ${ }^{5}$, 刘云慧 ${ }^{6}$, 宇振荣 ${ }^{6}$

1. 西南大学农学与生物科技学院，重庆 400715; 2. 农业农村部农业生态与资源保护总站，北京 100125; 3. 宁波市农产品质量安全管理总 站，浙江宁波 315012; 4. 宁波市农业科学研究院，浙江宁波 315040; 5. 宁波天胜农牧发展有限公司，浙江宁波 315012; 6. 中国农业大学资 源与环境学院, 北京 100193

摘要: 农田节肢动物多样性具有病虫害控制、传粉等价值, 选择一种或多种适宜、准确且高效的取样方法和指示类群来衡量 农田节肢动物多样性是一项基础性工作。本文通过地表陷阱法、挂盆陷阱法、扫网法、目测计数法和吸虫器法在有机管理和 常规管理农田区的不同农业生境类型中取样, 比较不同方法对不同生物类群的捕获效率、经济成本、响应敏感性等。研究发 现在捕获效率方面, 地陷法和挂盆法最高, 其次是扫网法, 而吸虫器法和目测计数法较差。挂盆法对步甲、蜘蛛、蜂类和慓 虫类群的捕获效率较佳。陷阱法主要适用于蜘蛛和步甲的取样, 扫网法也可用于蜘蛛和漂虫的取样。在经济成本方面, 地陷 法的成本最低, 扫网法的总成本最高。每种取样方法下仅有个别类群个体数量具有较好的响应敏感性, 如地陷法的蜘蛛目个 体数和步甲科个体数、挂盆法的总个体数、蜂类个体数和墂虫科个体数、扫网法的直翅目个体数和半翅目个体数等。在此基 础上, 综合类群经济价值, 操作难易, 类群鉴定难度, 被动取样程度, 是否受取样人影响等比较发现: 地陷法对步甲和蜘蛛的 取样的综合效果最佳, 而不同取样方法下多种类群的组合能更好地监测和评价农田节肢动物多样性的整体情况。地陷法捕获 步甲或/和蜘蛛以及挂盆法调查蜂类的组合是基于本研究得出的调查农田节肢动物多样性的最佳组合。

关键词: 节肢动物; 取样方法; 农田生物多样性; 农田生态系统; 农业昆虫

段美春, 覃如霞, 张宏斌, 陈宝雄, 金涁, 张松泊, 任少鹏, 金树权, 朱升海, 华家宁, 刘云慧, 宇振荣 (2021) 农田节肢动物不同取样方法的综合比较. 生物多样性, 29, 477-487. doi: 10.17520/biods.2020034.

Duan MC, Qin RX, Zhang HB, Chen BX, Jin B, Zhang SB, Ren SP, Jin SQ, Zhu SH, Hua JN, Liu YH, Yu ZR (2021) Comprehensive comparison of different sampling methods for arthropod diversity in farmland. Biodiversity Science, 29, 477-487. doi: 10.17520/biods.2020034.

\section{Comprehensive comparison of different sampling methods for arthropod diversity in farmland}

Meichun Duan ${ }^{1}$, Ruxia Qin ${ }^{1}$, Hongbin Zhang ${ }^{2}$, Baoxiong $\mathrm{Chen}^{2 *}$, Bin $\mathrm{Jin}^{3}$, Songbo Zhang ${ }^{3}$, Shaopeng Ren ${ }^{4}$, Shuquan $\mathrm{Jin}^{4}$, Shenghai Zhu ${ }^{5}$, Jianing $\mathrm{Hua}^{5}$, Yunhui Liu ${ }^{6}$, Zhenrong $\mathrm{Yu}^{6}$

1 College of Agronomy and Biotechnology, Southwest University, Chongqing 400715

2 Rural Energy and Environment Agency, Ministry of Agriculture and Rural Affairs, Beijing 100125

3 Ningbo Agricultural Products Quality and Safety Management Station, Ningbo, Zhejiang 315012

4 Ningbo Academy of Agricultural Sciences, Ningbo, Zhejiang 315040

5 Ningbo Tiansheng Farming Development Co., Ltd, Ningbo, Zhejiang 315012

6 College of Resources and Environmental Sciences, China Agricultural University, Beijing 100193

\section{ABSTRACT}

Aims: Arthropod biodiversity in farmlands has considerable value in terms of pest control, pollination, and other ecological services. To adequately assess arthropod biodiversity in farmlands, a fundamental step to select appropriate, accurate, and efficient sampling methods and identify appropriate indicator taxa.

Methods: Here, we compared several arthropod sampling methods in different types of agricultural habitats within organic managed and conventional managed farmland, including the surface trap cup method, coloured pan traps,

收稿日期: 2020-02-03; 接受日期: 2020-06-09

基金项目: 国家自然科学基金(41901218)、国家重点研发计划课题(2018YFC0507203)和中央高校基本科研业务费(XDJK2019C098)

* 通讯作者 Author for correspondence. E-mail: cbxiong@126.com 
the sweeping method, visual counting, and the vacuum-suction method. We compared the capture efficiency, economic costs, and response sensitivity of each method for different species assemblages.

Results: We found that the surface trap cup method and coloured pan traps had the highest capture efficiency, followed by the sweeping method, the vacuum-suction method, and visual counting, which had the lowest capture efficiency. Coloured pan traps was more efficient at capturing carabids, spiders, bees, and ladybugs. The surface trap cup method was mainly applicable to sampling ground spiders and carabids. The sweeping method was also effective at sampling spiders and ladybugs. In terms of economic costs, the most economical method was the surface trap cup method, which was used to capture carabids or spiders. The sweeping method had the highest cost due to its low capture efficiency of spiders. Sampling methods varied in their response sensitivity and were reasonably able to estimate abundances only of certain taxa (e.g., the number of spiders and carabids by the surface trap cup method, the total number of specimens, the number of bees, and the number of ladybugs by coloured pan traps, and the number of Orthoptera and Hemiptera by the sweeping method).

Conclusion: We further compared sampling methods after taking into account the economic value of the taxon, the difficulty of sampling operation, the difficulty of taxon identification, the degree of passive sampling, and whether the taxon was influenced by different individuals conducting the sampling. The most comprehensive method was the surface trap cup method targeting carabids and spiders. Using a combination of different sampling methods for multiple taxa is recommended to comprehensively evaluate and monitor overall farmland arthropod biodiversity, and our results suggest that the best combination includes sampling carabids and spiders using the surface trap cup method and sampling bees using coloured pan traps.

Key words: arthropod; sampling methods; farmland biodiversity; agricultural ecosystem; agricultural insect

农田生物多样性(farmland biodiversity)特指农 田生态系统中的生物多样性, 可以理解为在农田进 行生长、繁殖、栖息、取食、迁移、避难等活动的 所有物种及其相互间复杂的营养级联系(Fahrig et al, 2011)。节肢动物是农田中最多的类群, 其中步甲、 蜘蛛、蝴蝶、蜜蜂、漂虫和食蚜蝇常被作为生物多 样性指示类群(Dennis et al, 2012; Fahrig et al, 2015; Duan et al, 2019)。农田节肢动物及其提供的生态系 统服务(如生物控制、授粉等)是农业可持续发展的 基础(尤民生等, 2004; 李正跃等, 2009), 为人类带 来巨大经济利益(Costanza et al, 1998; Altieri, 1999; Tscharntke et al, 2005), 例如传粉昆虫使全球124种 作物产量提高了 $70 \%$, 影响了全球35\%的食物供给 (Klein et al, 2003)。虽然集约化的农业生产方式对于 粮食产量的增加发挥了巨大作用, 却成为农田生物 多样性下滑和生态系统服务功能丧失的主要原因 之一(Pimentel et al, 1992; Benton et al, 2003; Kleijn et al, 2009)。因此, 保护和恢复农田生态系统中的节 肢动物多样性刻不容缓 (Butler et al, 2007; Concepción et al, 2012)。

监测和评价是实现农田生物多样性保护的前 提条件。相对于自然生态系统, 农田生态系统中的 节肢动物多样性同样广泛而丰富。我国旱地农业生 态系统有害动物及昆虫有 1,300 多种、捕食性节肢动
物约2,000种, 仅棉田蜘蛛就有205种(章家恩, 1999), 稻田蜘蛛多达372种(王洪全等, 1996)。因此面对丰 富多样的农田生物多样性, 如何选择最合适的节肢 动物采集方法一直是探讨的话题(吴进才等, 1993; Zou et al, 2012; 黄杰灵等, 2013)。

全面调查所有农田节肢动物类群是不现实的 (刘向东, 2013)。农田中蜂类、步甲、蜘蛛和慓虫种 群数量大、种类丰富、对环境干扰敏感, 是农田生 物多样性调查和评估最广泛选择的类群(Rainio \& Niemelä, 2003; Belfrage et al, 2005; Dennis et al, 2012)。针对不同的生物类群乃至同一生物类群都有 不同的取样调查方法, 挂盆陷阱法(挂盆法/彩盘 法)、地表陷阱法(地陷法)、扫网法、目测计数法(目 测法)、吸虫器法和马氏网法是节肢动物取样常用的 方法。不同取样方法的比较主要是从捕获效率, 如 物种数或功能群的多度(吴进才等, 1993; 黄杰灵等, 2013; 王宇等, 2016), 以及操作难易程度来衡量其 优劣(章康华和钟玲, 1992)。通过不同取样方法的主 动与被动性, 取样有无 “活动密度”来进行比较, 并 定性评价取样方法的成本和不足(Zou et al, 2012)。 同时, 生物指示类群还要求其对于环境变化具敏感 性, 也就是说在取样地生态环境好、受到人为干扰 较少的地方, 该类群就具有较高多样性; 如果取样 地受人为干扰影响较大、生态环境较差, 那么该类 
群的多样性就应该低。因此某一方法下某一类群的 多样性高低能否反映不同干扰梯度下的差异, 即其 对干扰等的响应敏感性, 也是评价不同方法优劣的 因素之一(Dennis et al, 2012; Duan et al, 2016b)。目 前, 综合考虑以上诸多因素的研究较为缺乏。因此 综合比较以上因素, 选出标准、专业、快速、可重 复、低成本、高效率的方法十分重要(黄杰灵等, 2013; 刘向东, 2013)。

本研究通过定量化综合比较几种常见的农田 生物多样性调查方法及其类群的捕获效率、操作鉴 定难易、经济时间成本、响应敏感性及准确性等差 异, 旨在探讨: (1)每种方法适宜的取样类群及捕获 效率; (2)某一方法下该类群多样性指数的响应敏感 性; (3)效果最优的一个或多个取样方法和类群。以 期找到简单、准确、高效的农田生物多样性标准化 调查取样方法, 比较和评估不同地方的农田生物多 样性, 为保护和恢复农田生物多样性及其服务功能 提供参考。

\section{材料与方法}

\section{1 研究区及样地设置}

为衡量不同取样方法及类群对于农田干扰梯 度的响应敏感性, 设置有机管理和常规管理区及代 表不同干扰梯度的生境类型。研究区在浙江省宁波 市鄞州区古林镇, 该地区属亚热带季风气候, 地形 以平原为主, 水系丰富, 土壤以红壤和黄壤为主, 土层较厚。

有机管理区位于古林镇前虞村 $\left(29^{\circ} 80^{\prime} \mathrm{N}\right.$, $\left.121^{\circ} 40^{\prime} \mathrm{E}\right)$ 的天胜农牧“四不用”农场, 总面积 1,030 亩; 农场自2011年建立至今一直由公司统一经营并 实行有机管理, 不施用化肥和农药。大棚蔬菜地一 年种植 2 轮蔬菜, 露天田块每年种植蔬菜或作物 1 轮, 水稻田一年内进行水稻小麦轮作, 均施用自制湿基 有机肥。果园进行林下养鸡, 50只/亩, 每年机器割 草1次。

常规管理区位于有机农场以西约 $5 \mathrm{~km}$ 的古林 镇共任村 $\left(29^{\circ} 81^{\prime} \mathrm{N}, 121^{\circ} 45^{\prime} \mathrm{E}\right)$, 调查区总面积约 1,000亩; 该村土地由村民各自进行集约化种植管 理。大棚蔬菜地年种植绿叶蔬菜6轮, 施用复合肥约 $125 \mathrm{~kg} /$ 亩, 年喷酒农药约5次。露天田块一年一般种 植2轮蔬菜为主, 施用化肥复合肥 $40 \mathrm{~kg}$ /亩, 喷酒农 药约3次。水稻田一年内进行水稻席草轮作, 施用氮
肥 $15 \mathrm{~kg} /$ 亩, 复合肥 $25 \mathrm{~kg} /$ 亩, 喷酒农药约4次。对照 地选择的 3 个果园生境管理较为粗放, 近两年未施 用化肥和农药(孙玉芳等, 2019)。

在两个农田管理区都分别选择大棚蔬菜(DC)、 果园(GY)、水稻田埂(SD)、露天田块(LC)和露天田 块边缘的农田边界(NB)共5种生境类型。每种生境 类型设置3个重复, 合计 30 块样地。每块样地面积在 $100 \mathrm{~m}^{2}$ 以上, 样地之间间隔 $100 \mathrm{~m}$ 以上(露天田块及 其农田边界除外)。在果 园、露天田块两类面状生境 样地中心设置 1 块 $10 \mathrm{~m} \times 10 \mathrm{~m}$ 的样方, 在大棚蔬菜、 农田边界和水稻田埂等线状生境样地中心设置1条 $2 \mathrm{~m} \times 50 \mathrm{~m}$ (或 $1 \mathrm{~m} \times 100 \mathrm{~m}$ )的样带。

\section{2 节肢动物不同类群调查方法}

\subsection{1 地表陷阱杯法(地陷法)}

用埋入地表的陷阱杯对地表节肢动物进行取 样。在面状生境采用五点法对每个样方设置 5 个陷 阱杯。在线状样地沿着样带中间每间隔 $5 \mathrm{~m}$ 分别放 置 5 个陷阱杯。陷阱杯为高度 $12 \mathrm{~cm}$ 、杯口直径 $8 \mathrm{~cm}$ 的硬质塑料杯。杯内倒入 $1 / 3$ 的饱和食盐水, 添加几 滴洗洁精以破坏液面的表面阻力。使容器边缘稍低 于或与土壤表面持平, 并在容器上方 $5 \mathrm{~cm}$ 处支撑一 块有机玻璃片作为防雨罩。每周收集标本并更换溶 液。

\subsection{2 挂盆陷阱法(挂盆法)}

用挂盆陷阱法对空中飞行节肢动物进行取样。 在每个面状生境内设置 9 个陷阱盆, 分别置于样方 为 $2 \mathrm{~m}$ 的小栅格交叉点上, 在每个交叉点分别间隔 放置黄白蓝色盆形陷阱。在每个线状生境监测点分 别设置1条50 m长的样带, 每条样带上相间放置黄 白蓝盆形陷阱各 3 个, 每个陷阱至少间隔 $2 \mathrm{~m}$, 两端 的陷阱距样带端部至少 $5 \mathrm{~m}$ 。将上口径为 $21 \mathrm{~cm}$ 、高 为 $12.5 \mathrm{~cm}$ 的盆形陷阱挂在长 $1.5 \mathrm{~m}$ 的支架上, 支架 插入地下约 $30 \mathrm{~cm}$ 固定。陷阱中放入 $300 \mathrm{~mL}$ (约盆的 1/4)饱和食盐水和少量洗洁精。每周收集标本并更 换溶液。

\subsection{3 扫网法}

用扫网法对空中节肢动物进行收集。在面状样 地内, 调查人员在样地内行走 $20 \mathrm{~min}$, 同时利用捕 虫网捕获节肢动物; 或两个人同时进行, 每人捕获 $10 \mathrm{~min}$ 。在线状样地样带内, 调查人员沿样带往返 行走 $20 \mathrm{~min}$, 以保证和面状样地的取样强度一致。 步行速度大约为 $6-7 \mathrm{~m} / \mathrm{min}$, 捕虫网网纱 80 目, 网口 
直径 $30 \mathrm{~cm}$, 网深 $55 \mathrm{~cm}$, 杆长 $110 \mathrm{~cm}$ 。取样于 9:30-17:30的晴天或微阴天、气温 $>15^{\circ} \mathrm{C}$ 、风速 $<$ $2.5 \mathrm{~m} / \mathrm{s}$ 的情况进行。

\subsection{4 目测计数法(目测法)}

采用目测计数法记录植株上的节肢动物。在面 状样地内随机选择 10 株距离边界至少 $2 \mathrm{~m}$ 的植物, 在线状样地内至少间隔 $1 \mathrm{~m}$ 随机选择 10 株植物。按 大类或能鉴定到的水平记录每个植株上各类节肢 动物的数量, 捕获的蜘蛛和甲虫放入装有 $80 \%$ 酒精 的离心管中并带回实验室进行鉴定。

\subsection{5 吸虫器法}

在稻田田埂样带边的稻田和露天菜地采用吸 虫器法调查节肢动物。在每个样地内随机设置 5 个 取样点(间隔 $2 \mathrm{~m}$ 以上)。采用经复叶式鼓风机(leaf blower-vac)改装的吸虫器抽吸节肢动物(Zou et al, 2016)。在每一个取样点用去底的塑料桶(底面直径 $40 \mathrm{~cm}$, 高 $40 \mathrm{~cm}$, 体积约 $50 \mathrm{~L}$ ), 上部带纱网罩, 防 止节肢动物逃逸。用桶快速地罩住2-4从水稻或其 他植物, 再用吸虫器吸取 $2 \mathrm{~min}$ 。将取到的节肢动物 装入 $80 \%$ 的酒精保存并带回实验室分类鉴定。

所有节肢动物标本依据《中国亚热带土壤动 物》(尹文英, 1992)、《中国土壤动物检索图鉴》(尹 文英, 1998)、《昆虫分类(上、下)》(郑乐怡和归鸿, 1999)和《昆虫分类学(修订版)》(蔡邦华等, 2017) 分类至目, 并统计步甲科、漂虫科、金龟子科、蜘 蛛目、蜂类在各样地的个体数。

\section{3 不同取样方法的比较}

(1)不同取样方法的捕获效率, 采用单因素方 差分析。包括3部分: (i) 不同方法对常见目级节肢动 物类群捕获效率差异。将7月27日至8月4日持续一 周的挂盆法和地陷法获得的数据和7月29日至8月3 日间采用目测法和扫网法一轮取样获得的数据进 行比较, 探讨不同取样方法在相似的采样强度下 (主要是采集人的田间时间投入, 如布置陷阱或操 作设备的时间)的捕获不同生物类群的个体数差异。 (ii)不同方法对常用指示类群(蜘蛛、步甲、慓虫、 金龟子、蜜蜂等)捕获效率的差异。将采用挂盆法和 地陷法在5月28日至6月11日、7月27日至8月24日共 计6周的取样数据, 5月29日至6月2日、7月29日至8 月3日、8月23-25日共3次扫网法的数据, 和5月 29 日至6月2日，7月29日至8月3日共2次的目测法数据 进行比较。(iii)吸虫器法与其他方法的捕获效率的
差异。由于吸虫器法仅在 8 月 26 日对露天农田和水 稻田两种生境共12个样地取样, 所以只利用水稻田 和露天田块的 8 月 17-24日一周的挂盆法和地陷法, 以及8月23-25日间扫网法的取样数据进行比较。

(2)取样成本差异。基于所有 30 个样地采用地陷 法和挂盆法进行 1 次, 持续取样 2 周(从布置取样仪 器, 中间收标本和换液, 到最后回收仪器)的调查成 本, 扫网法调查和目测计数法调查 1 轮(每个样地调 查1次)的人力成本、交通成本和器材成本进行比较, 人力成本还包括田间取样和室内挑选、制作、统计 分类标本的时间成本。考虑到不同方法捕获效率的 差异, 最后综合换算成每种方法要达到平均一个样 地50只蜘蛛(几种方法捕获量都很多, 且是农田常 用指示类群)所需要进行取样次数后的总成本。

(3)相同取样方法下某一生物类群的响应敏感 性。如果某方法下某类群的个体数符合有机管理高 于常规管理, 且农田边界、水稻田埂和果园(粗放管 理, 非集约化生境)高于露天农田, 更高于大棚菜地 (集约化管理生境)的规律, 则认为该方法下该类群 有较好的响应敏感性, 即对环境梯度或干扰敏感 (Dennis et al, 2012; Duan et al, 2016a)。我们采用个 体数而不是物种数作为多样性指标, 因为鉴定所有 的标本到物种水平是很困难的。已完成鉴定的蜘蛛 和蜂类分析标本, 其个体数和物种数之间具有显著 的正相关性, Pearson相关分析结果分别为 $r=0.59$, $P<0.01$ 和 $r=0.84, P<0.01$ 。衡量不同取样方法及 类群对于农田干扰梯度的响应敏感性差异, 采用双 因素方差分析。在方差分析前, 先进行物种数据的 正态性和方差齐性检验。多重比较选用Tukey检验 法, 方差分析在SPSS 16.0软件中进行。

(4)对不同取样方法的综合比较。综合以上三方 面内容, 我们分别对每种方法下的9项评价标准分 别赋予权重, 包括: 指示类群的捕获效率 $(10 \%)$ 、取 样经济成本 $(10 \%)$ 、响应敏感性(20\%)、类群经济价 值(对农业生产的直接价值, 如是否具有病虫害控 制功能、传粉功能等) (10\%)、操作难度 $(10 \%)$ 、专 家田间支持 $(10 \%)$ 、鉴定难度 $(10 \%)$ 、被动取样程度 (主动取样需要人工捕获, 被动取样不需要人工捕 获) $(10 \%)$ 、受取样人影响(取样人差异是否会显著影 响取样结果) (10\%)。对以上9项进行打分(1-3分), 其中捕获效率、响应敏感性、类群经济价值、被动 取样程度等这4项的“低 中、高”三个级别分别记为 
1、2、3分; 而操作难度、取样经济成本、专家田间 支持、鉴定难度和受取样人影响等这 5 项的“低、中、 高”三个级别分别记为3、2、1分。根据权重计算综 合得分, 得分 $>2.5$ 则建议入选, 推荐作为代表方法 和和代表指示类群; 得分 $<2.5$ 则不推荐。

\section{2 结果}

\section{1 不同取样方法的捕获效率比较}

\subsection{1 不同方法对常见目级类群的捕获效率差异}

总个体数和常见 7 个类群的个体数在不同取样 方法间均存在显著性差异 $(\mathrm{df}=3, F=4.0-16.7, P<$ 0.009 , 表1)。多重比较发现, 挂盆法和地陷法捕获 总个体数差异不显著, 但都显著大于扫网法(表1)。 目测法发现 3,000 多只节肢动物, 但蚜虫数量超过 半数, 而其他鞘翅目、蜘蛛、蜂类等常用指示类群 数量少。从目级类群上看, 挂盆法对双翅目、膜翅 目、鞘翅目和蜘蛛目昆虫的捕获效果都较好; 地陷 法适用于蜘蛛目、鞘翅目和膜翅目 (主要是蚂蚁); 扫网法捕获半翅目、蜘蛛目和双翅目的效果较好, 而对鳞翅目和膜翅目效果较差。

\subsection{2 不同方法对常用指示类群捕获效率的差异}

除图中所列多数类群外(图1), 还捕获113只隐 翅虫、201只食蚜蝇、90只埋葬甲、54只蜻蜓, 但这 些取样方法对这几个类群的捕获效率太低, 因此未 进行方差分析。鞘翅目中金龟子(658只)和叶甲(503 只)数量虽多, 但 $70 \%$ 以上都是植食性害虫(如棕色 鳃金龟Holotrichia titanis 和黄守瓜 Aulacophora indica)。

常用的 5 个指示类群的个体数在不同取样方法
间均存在显著性差异 $(\mathrm{df}=3, F=26.0-83.4, P<$ 0.001)。多重比较发现，对于蜘蛛捕获量，扫网法和 目测法显著低于挂盆法和地陷法(图1)。对蜂类、漂 虫和金龟子的捕获效率最高的方法是挂盆法，且蜂 类只适合挂盆法。对于步甲，挂盆法和地陷法的捕 获效率差异不大。扫网法捕获蜂类、金龟子和步甲 的效率较低, 但对于漂虫的取样效率较高。

\subsection{3吸虫器法在露天农田和稻田的取样效率和} 其他方法比较

对于膜翅目(含蜂类)和鞘翅目的漂虫、步甲、

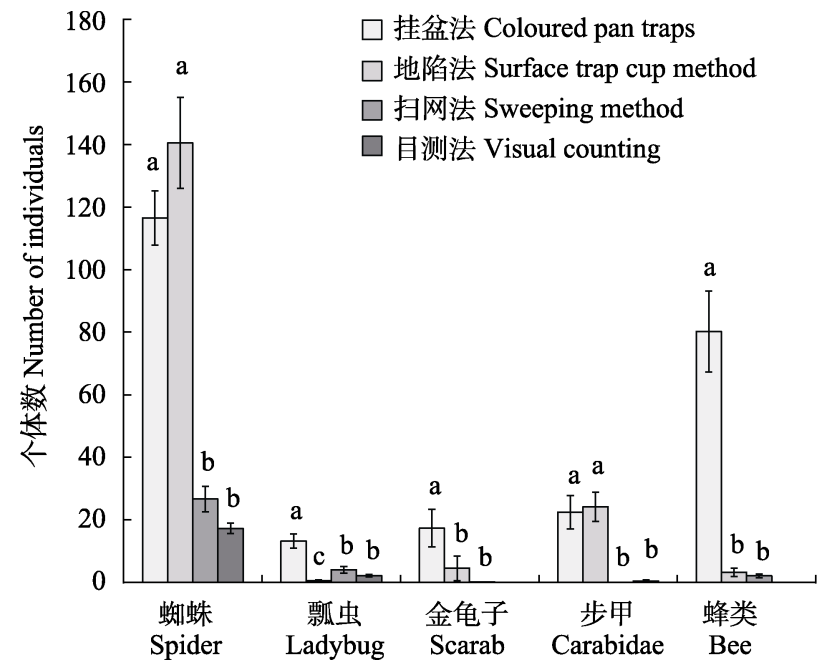

图1 不同取样方法捕获常见指示类群个体数量的差异(图 中柱上有不同字母表示不同方法之间的捕获数量差异显著) Fig. 1 Differences in the number of individuals in common indicator groups captured by different sampling methods. For each group, bars sharing different superscript letters were significantly different at $P<0.05$ (Tukey HSD post hoc tests) in the same blow.

表1 挂盆法、目测法、地陷法和扫网法的常见目级类群捕获效率差异(个体数单位: 个)

Table 1 The difference in the number of common taxa of coloured pan traps, visual counting, surface trap cup method, and sweeping method (unit: PCS)

\begin{tabular}{|c|c|c|c|c|}
\hline & 挂盆法 Coloured pan traps & 目测法 Visual counting & 地陷法 Surface trap cup method & 扫网法 Sweeping method \\
\hline 鞘翅目 Coleopteran & $16.32 \pm 3.74^{\mathrm{a}}$ & $4.73 \pm 0.89^{b}$ & $12.83 \pm 3.35^{\mathrm{a}}$ & $5.10 \pm 0.68^{\mathrm{b}}$ \\
\hline 蜘蛛目 Araneae & $18.36 \pm 2.15^{\mathrm{a}}$ & $6.92 \pm 0.90^{\mathrm{c}}$ & $23.52 \pm 3.22^{\mathrm{a}}$ & $13.79 \pm 2.17^{\mathrm{b}}$ \\
\hline 鳞翅目 Lepidoptera & $5.27 \pm 1.39^{\mathrm{a}}$ & $0.40 \pm 0.11^{\mathrm{c}}$ & $0.90 \pm 0.25^{b}$ & $0.27 \pm 0.20^{c}$ \\
\hline 膜翅目 Hymenoptera & $36.64 \pm 10.19^{\mathrm{a}}$ & $15.05 \pm 2.59^{b}$ & $46.81 \pm 10.28^{\mathrm{a}}$ & $2.53 \pm 0.48^{\mathrm{c}}$ \\
\hline 双翅目 Diptera & $49.46 \pm 14.62^{\mathrm{a}}$ & $3.55 \pm 0.66^{c}$ & $11.25 \pm 1.97^{\mathrm{b}}$ & $5.40 \pm 1.36^{\mathrm{c}}$ \\
\hline 直翅目 Orthoptera & $4.22 \pm 1.09^{\mathrm{b}}$ & $3.18 \pm 0.45^{\mathrm{b}}$ & $14.59 \pm 2.42^{\mathrm{a}}$ & $4.29 \pm 0.86^{\mathrm{b}}$ \\
\hline 半翅目 Hemiptera & $10.00 \pm 1.94^{\mathrm{a}}$ & $6.56 \pm 2.06^{\mathrm{b}}$ & $3.11 \pm 0.69^{c}$ & $15.81 \pm 3.09^{\mathrm{a}}$ \\
\hline $\begin{array}{l}\text { 总个体数 Total number } \\
\text { of individuals }\end{array}$ & $125.67 \pm 21.11^{\mathrm{a}}$ & $100.60 \pm 25.81^{\mathrm{a}}$ & $98.23 \pm 13.88^{\mathrm{a}}$ & $39.50 \pm 4.70^{\mathrm{b}}$ \\
\hline
\end{tabular}

同一行中不同字母表示差异显著 Different letters in the same row indicate significant difference 
金龟子等类群，吸虫器法取样效率低(见附录1)。吸 虫器法单次取样的总个体数和鞘翅目个体数虽显 著低于挂盆法, 但与地陷法、扫网法相差不大(图2)。 对于蜘蛛, 吸虫器法除显著地高于目测法外, 和其 他方法的取样效率差异都不显著。

\section{2 不同取样方法的成本比较}

目测法单次调查成本最低, 其次是扫网法和吸 虫器法; 但由于捕获效率低, 目测法和扫网法需要 6 次、吸虫器法需要4次才能达到一个样地平均 50 只 蜘蛛的取样量, 因此总成本更高。地陷法和挂盆法 捕获50只蜘蛛只需1.5次 (即3周), 总成本较低, 且还 可有效捕获步甲或蜂类。

\section{3 不同方法下不同类群响应敏感性的差异}

符合常规农业措施和高干扰生境的生物多样 性显著更低这一预期的结果有：挂盆法总个体数、 直翅目、慓虫数、膜翅目、蜂类、步甲数、半翅目 和金龟子个体数; 扫网法直翅目个体数; 地陷法蜘 蛛目个体数、步甲科个体数, 其中地陷法步甲个体 数响应敏感性最佳(表 3 , 其他不符合预期的结果见 附录2)。

\section{4 不同方法的综合比较}

由表4可见，挂盆法的蜘蛛捕获效率虽高，但 响应敏感性差, 不建议采用。目测计数法受人为取
样干扰明显，且移动迅速的节肢动物容易逃逸，不 建议采纳。扫网法捕获效率一般，成本较高，预测 效果一般，也受到一定的人为干扰，不建议选。吸 虫器法捕获效率一般, 田间操作难度较大, 不建议 选。蜘蛛、蜜蜂鉴定费用较高且难度大; 步甲大部 分能通过自学鉴定，单价也相对便宜，建议采用。

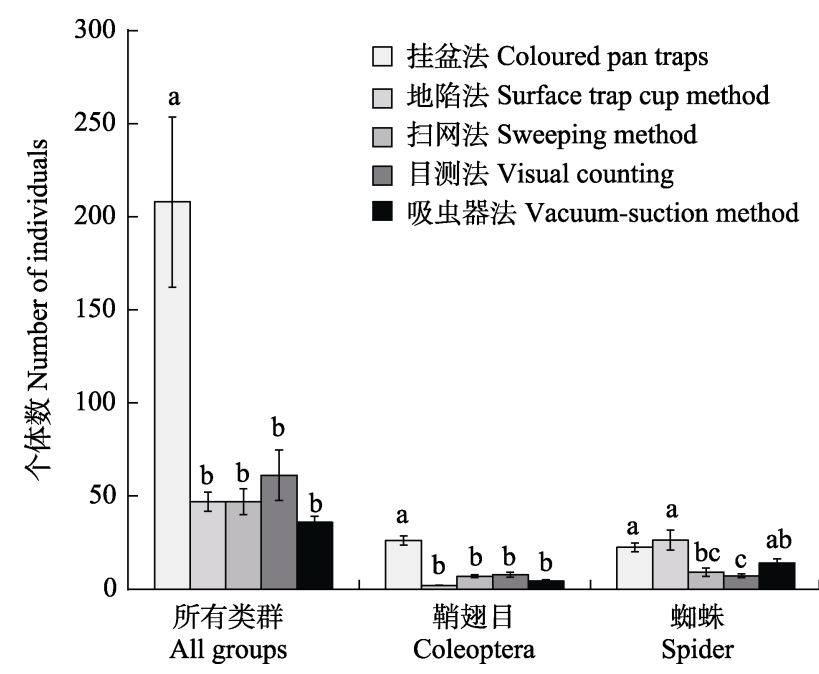

图2 吸虫器法和其他取样方法捕获常见指示类群个体数量 的差异

Fig. 2 Differences in the number of individuals in common indicator groups captured by vacuum-suction method and other sampling methods

表2 不同方法取样成本统计表

Table 2 Statistics of sampling cost by different methods

\begin{tabular}{|c|c|c|c|c|c|}
\hline & $\begin{array}{l}\text { 挂盆法 } \\
\text { Coloured pan trap }\end{array}$ & $\begin{array}{l}\text { 地陷法 Surface trap } \\
\text { cup method }\end{array}$ & $\begin{array}{l}\text { 目测法 } \\
\text { Visual counting }\end{array}$ & $\begin{array}{l}\text { 扫网法 } \\
\text { Sweeping method }\end{array}$ & $\begin{array}{l}\text { 吸虫器法 } \\
\text { Vacuum-suction method }\end{array}$ \\
\hline $\begin{array}{l}\text { 样地取样量(个) Sampling } \\
\text { amount (PCS) }\end{array}$ & 1,165 & 1,413 & 259 & 266 & 775 \\
\hline $\begin{array}{l}\text { 田间费时(时) Time consuming } \\
\text { in the field (Hour) }\end{array}$ & 60 & 48 & 29 & 27 & 30 \\
\hline $\begin{array}{l}\text { 室内费时(时) Time consuming } \\
\text { indoor (Hour) }\end{array}$ & 30 & 30 & 2 & 10 & 10 \\
\hline 租车(天) Total rental time (Day) & 3 & 3 & 2 & 2 & 2 \\
\hline 人工费用(元) Labor cost (RMB) & 2,250 & 1,950 & 775 & 925 & 1,000 \\
\hline $\begin{array}{l}\text { 租车费用(元) Car rental cost } \\
\text { (RMB) }\end{array}$ & 1,500 & 1,500 & 1,000 & 1,000 & 1,000 \\
\hline $\begin{array}{l}\text { 单次取样成本(元) Cost of one } \\
\text { sampling (RMB) }\end{array}$ & 3,750 & 3,450 & 1,775 & 1,925 & 2,000 \\
\hline 取样次数 Sampling times & 1.5 & 1.5 & 6 & 6 & 4 \\
\hline $\begin{array}{l}\text { 样地取样成本(元) Sampling cost } \\
\text { (RMB) }\end{array}$ & 5,625 & 5,175 & 10,650 & 11,550 & 8,000 \\
\hline $\begin{array}{l}\text { 器材成本(元) Equipment cost } \\
\text { (RMB) }\end{array}$ & 3,676 & 1,574 & 45 & 1,202 & 2,500 \\
\hline 总成本(元) Total cost (RMB) & 9,301 & 6,749 & 10,695 & 12,752 & 10,500 \\
\hline
\end{tabular}


表3 生物多样性指标在不同管理措施和生境下 $F$ 检验都存在显著性差异时不同水平间的多重比较(单位: 个)

Table 3 The post hoc tests of biodiversity indicators in different levels when $\mathrm{F}$ test were significant under both different management measures and different habitats types

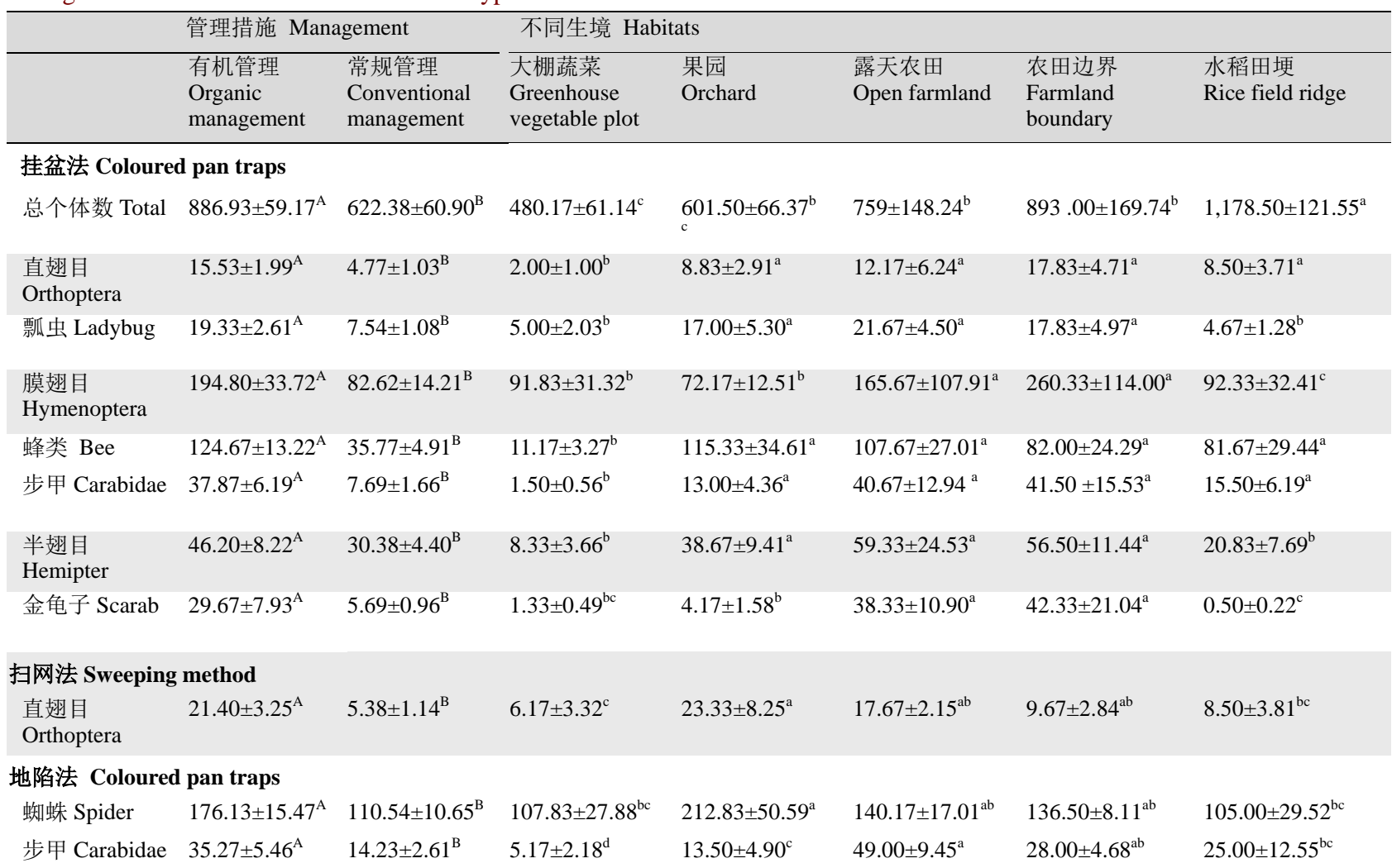

同一行不同大写字母代表该方法下该类群的个体数在不同管理措施下存在显著性差异, 不同小写字母表示该指标在不同生境间存在显著性 差异 $(P<0.05)$ 。Different capital letters on the same low represent the significant difference of the number of individuals in this group under different management measures, and different lowercase letters represent the significant difference of the index among different habitats $(P<0.05)$.

综合而言, 用挂盆法取样蜂类、慓虫和步甲, 地陷 法取样步甲和蜘蛛是较优的取样方法及调查类群。

\section{3 讨论}

以往研究发现, 每种方法都有各自适宜的捕获 类群, 而非对所有节肢动物类群都有效(黄杰灵等, 2013; 王宇等, 2016)。蜻蜓、隐翅虫和食蚜蝇虽是 农田益虫, 但本研究中挂盆法、地陷法和扫网法捕 获的数量都太少, 因此暂不考虑将其作为农田生物 多样性指示类群。鳞翅目、双翅目、直翅目和半翅 目的捕获数量虽很多, 且具有较好的响应敏感性, 但由于鉴定困难且是农田植食性害虫类群, 我们推 荐采用它们相同取样强度下的个体数作为衡量多 样性的指标; 因为不仅个体数和物种数之间大都有 较强的相关性, 而且不同功能群的个体数多少也代 表了整个节肢动物群落的虫害程度、病虫害控制或 传粉等潜力(Tscharntke et al, 2005)。
类似每种方法有其擅长的捕获昆虫功能团/组, 例如挂盆法用于膜翅目传粉昆虫取样, 地陷法用于 甲虫取样(Dennis et al, 2012; 周红章等, 2014; Fahrig et al, 2015), 本研究也发现每种方法适合对 某一种或几种类群取样, 如挂盆法适合飞行蜂类昆 虫。挂盆法通过不同的颜色吸引不同的低空飞行生 物, 在传粉昆虫的研究中使用较多(王润等, 2017; 伍盘龙等, 2018)。不同颜色有各自的吸引对象, 如 蓝盆比黄盆陷阱更吸引冠蜂科蜂类, 白盆比黄盆更 吸引双翅类昆虫(Zou et al, 2012)。降雨会影响挂盆 法捕获效率和标本保存, 需定期检查。本研究中挂 盆法对蜂类的捕获效率不太理想, 可增加取样次数 或在开花季节传粉蜂类较多时调查。挂盆法的蜘蛛 数量在不同管理措施和不同生境间都没有显著差 异, 捕获到的蜘蛛可能是随气流随机扩散而来, 因 此受到管理措施和生境类型的影响很小。挂盆法对 步甲和瓢虫也具有较好捕获效果, 可在今后的研究 
表4 基于加权得分的不同取样方法的综合比较

Table 4 Comprehensive comparison of different sampling methods based on weighted score

\begin{tabular}{|c|c|c|c|c|c|c|c|c|c|c|c|c|c|}
\hline & \multirow[t]{2}{*}{$\begin{array}{l}\text { 权重 } \\
\text { Weight }\end{array}$} & \multicolumn{4}{|c|}{$\begin{array}{l}\text { 挂盆法 } \\
\text { Coloured pan traps }\end{array}$} & \multicolumn{2}{|c|}{$\begin{array}{l}\text { 地陷法 } \\
\text { Surface trap cup } \\
\text { method }\end{array}$} & \multicolumn{2}{|c|}{$\begin{array}{l}\text { 目测法 } \\
\text { Visual counting }\end{array}$} & \multicolumn{3}{|c|}{$\begin{array}{l}\text { 扫网法 } \\
\text { Sweeping method }\end{array}$} & \multirow{2}{*}{$\begin{array}{l}\text { 吸虫器法 } \\
\text { Vacuum-suc } \\
\text {-tion method } \\
\text { 蜘蛛 } \\
\text { Spider }\end{array}$} \\
\hline & & $\begin{array}{l}\text { 蜂类 } \\
\text { Bee }\end{array}$ & $\begin{array}{l}\text { 漂虫 } \\
\text { Ladybug }\end{array}$ & $\begin{array}{l}\text { 蜘蛛 } \\
\text { Spider }\end{array}$ & $\begin{array}{l}\text { 步甲 } \\
\text { r Carabidae }\end{array}$ & $\begin{array}{l}\text { 步甲 } \\
\text { Carabidae }\end{array}$ & $\begin{array}{l}\text { 蜘蛛 } \\
\text { Spider }\end{array}$ & $\begin{array}{l}\text { 漂虫 } \\
\text { Ladybug }\end{array}$ & $\begin{array}{l}\text { 蜘蛛 } \\
\text { gSpider }\end{array}$ & $\begin{array}{l}\text { 蜂类 } \\
\text { Bee }\end{array}$ & $\begin{array}{l}\text { 蜘蛛 } \\
\text { Spider }\end{array}$ & $\begin{array}{l}\text { 直翅目 } \\
\text { Orthoptera }\end{array}$ & \\
\hline $\begin{array}{l}\text { 捕获效率 Capture } \\
\text { efficiency }\end{array}$ & $10 \%$ & 2 & 3 & 3 & 3 & 2 & 3 & 1 & 1 & 1 & 2 & 3 & 2 \\
\hline $\begin{array}{l}\text { 取样经济成本 } \\
\text { Economic cost of } \\
\text { sampling }\end{array}$ & $10 \%$ & 2 & 2 & 2 & 2 & 3 & 3 & 1 & 1 & 1 & 1 & 1 & 2 \\
\hline $\begin{array}{l}\text { 响应敏感性 } \\
\text { Response sensitivity }\end{array}$ & $20 \%$ & 3 & 3 & 1 & 3 & 3 & 3 & - & 1 & - & 1 & 3 & - \\
\hline $\begin{array}{l}\text { 类群经济价值 } \\
\text { Economic value of } \\
\text { groups }\end{array}$ & $10 \%$ & 3 & 3 & 3 & 2 & 2 & 3 & 3 & 3 & 3 & 3 & 1 & 3 \\
\hline $\begin{array}{l}\text { 操作难度 Operation } \\
\text { difficulty }\end{array}$ & $10 \%$ & 3 & 3 & 3 & 3 & 3 & 3 & 2 & 2 & 2 & 2 & 2 & 1 \\
\hline $\begin{array}{l}\text { 专家田间支持 Expert } \\
\text { field support }\end{array}$ & $10 \%$ & 3 & 3 & 3 & 3 & 3 & 3 & 2 & 2 & 2 & 3 & 3 & 3 \\
\hline $\begin{array}{l}\text { 鉴定难度 } \\
\text { Identification difficulty }\end{array}$ & $10 \%$ & 1 & 3 & 1 & 2 & 2 & 1 & 3 & 1 & 1 & 1 & 2 & 1 \\
\hline $\begin{array}{l}\text { 被动取样程度 Degree } \\
\text { of passive sampling }\end{array}$ & $10 \%$ & 3 & 3 & 3 & 3 & 3 & 3 & 1 & 1 & 1 & 1 & 1 & 2 \\
\hline $\begin{array}{l}\text { 受取样人影响 } \\
\text { Affected by sampling } \\
\text { people }\end{array}$ & $10 \%$ & 3 & 3 & 3 & 3 & 3 & 3 & 1 & 1 & 2 & 2 & 2 & 2 \\
\hline $\begin{array}{l}\text { 加权得分 Weighted } \\
\text { score }\end{array}$ & - & 2.6 & 2.9 & 2.3 & 2.7 & 2.7 & 2.8 & 1.4 & 1.4 & 1.3 & 1.7 & 2.1 & 1.6 \\
\hline $\begin{array}{l}\text { 建议入选 Recommend } \\
\text { for inclusion }\end{array}$ & & $\begin{array}{l}\text { 是 } \\
\text { Yes }\end{array}$ & $\begin{array}{l}\text { 是 } \\
\text { Yes }\end{array}$ & $\begin{array}{l}\text { 否 } \\
\text { No }\end{array}$ & $\begin{array}{l}\text { 是 } \\
\text { Yes }\end{array}$ & $\begin{array}{l}\text { 是 } \\
\text { Yes }\end{array}$ & $\begin{array}{l}\text { 是 } \\
\text { Yes }\end{array}$ & $\begin{array}{l}\text { 否 } \\
\text { No }\end{array}$ & $\begin{array}{l}\text { 否 } \\
\text { No }\end{array}$ & $\begin{array}{l}\text { 否 } \\
\text { No }\end{array}$ & $\begin{array}{l}\text { 否 } \\
\text { No }\end{array}$ & $\begin{array}{l}\text { 否 } \\
\text { No }\end{array}$ & $\begin{array}{l}\text { 否 } \\
\text { No }\end{array}$ \\
\hline
\end{tabular}

中进一步验证和发展。目前已经发展出营造昆虫巢 穴进行传粉昆虫调查和保护的方法, 效果比挂盆法 更好, 可在今后的研究中采用。

陷阱法是最常见的农田地表或半土生的节肢 动物调查与监测方法, 已成为调查地表步甲和蜘蛛 多样性的标准化方法(Rainio \& Niemelä, 2003; 周 红章等, 2014; Duan et al, 2019), 我们的研究也发现 地陷法最适合捕获地表步甲和蜘蛛。陷阱法具有操 作简单、取样效率高、成本低、对原有生境破坏小 等优点(黄杰灵等, 2013)。争议问题是陷阱杯中溶液 的选择: 有研究认为酒精存在强烈挥发性, 因而会 主动吸引某些物种如软体动物等; 而福尔马林、甲 醛等存在一定毒性和污染性(MacGavin, 1997)。因此 我们采用饱和食盐水, 该溶液配置方便、成本低, 也被其他研究采用(Zou et al, 2012; Bertrand et al, 2016)。但是降雨会稀释溶液, 影响标本保存效果, 建议更换溶液周期不超过1周。虽然有研究也在稻 田采用改进的陷阱法取样(施波等, 2011), 但地陷法
显然更适用于对旱地的节肢动物采样，与挂盆法同 时使用可取得更为全面的节肢动物取样结果。

基于调查方法的简易性和适用性，目测法最为 简单。多用在植物病虫害的调查, 但受人为扰动最 大, 不适用农田生物多样性的取样和调查。先前的 研究也表明目测法获得的各种害虫和天敌的数量 最少、准确性最差(章康华和钟玲, 1992), 我们的研 究也印证了目测法是所有方法中综合评价最低的。

扫网法常被用于鳞翅目蝴蝶和膜翅目蜂类的 取样(Dennis et al, 2012), 其成本低、操作简易，可 有效地比较小型低空节肢动物的多样性(Zou et al, 2012), 但捕获效率受到收集者影响较大，还受到天 气特别是风速的影响(MacGavin, 1997)。在本研究中, 扫网法对蜂类和蝴蝶的捕获效率都不理想, 不太适 合于该地区鳞翅目蝴蝶和膜翅目蜂类的调查。扫网 法对蜘蛛取样效果较好, 可以作为蜘蛛取样的备选 或补充方法, 特别是针对植被层的蜘蛛等节肢动物, 结合地陷法捕获地表蜘蛛, 总体效果更好(Zou et al, 
2012; Duan et al, 2019)。

吸虫器法被大量运用在稻田节肢动物采样中, 特别是稻田蜘蛛 (吴进才等, 1993; 刘雨芳等, 2002)。吸虫器法在稻田节肢动物取样中具有较高的 取样效率, 高于目测法和挂盆法, 低于马氏网法 (吴进才等, 1993; 王宇等, 2016)。在本研究中, 该方 法取样效率与挂盆法、地陷法差异不大。以前的研 究通常采用弥雾机改装的吸虫器取样, 容易造成部 分标本的破碎(吴进才等, 1993; 刘雨芳等, 1999; 刘 向东, 2013), 采用经过吹风机改装的吸虫器可避免 此现象(Zou et al, 2016)。采用去底的塑料桶且带纱 网罩快速地罩住植物, 再用吸虫器吸取 $2 \mathrm{~min}$, 基本 能保证被罩住的昆虫全部被吸虫器收集(Zou et al, 2016)。因此, 这样的操作对不同体型个体都能充分 取样, 而且可以定量地衡量单位面积上的节肢动物 多样性。但吸虫器法捕获的节肢动物个体数对环境 响应敏感性较差, 且操作复杂, 并受到人为操作的 影响, 会惊飞一些节肢动物(王宇等, 2016)。吸虫器 价格较贵、组装麻烦, 且笨重不易携带(Zou et al, 2012; 刘向东, 2013); 在旱地不能很好地实现底部 的封闭, 常导致部分节肢动物逃逸, 且在密植高秆 作物地(如玉米地)中操作不便, 因此不建议在旱地 农田中采用。

根据不同的调查目的和要求, 可选择不同的调 查方法和类群(Zou et al, 2012; 王宇等, 2016)。对于 数据要求高的科学研究, 稻田害虫和天敌的调查可 以采用吸虫器法, 而一般性调查可选用目测法(章 康华和钟玲, 1992)。相对于采用单一方法捕获的单 一生物类群进行农田生物多样性评价, 多种不同的 取样方法下不同生物类群的组合会有更好的效果 (Zou et al, 2012; 王宇, 2016)。例如Winkler法和陷阱 法的同时使用有利于获取不同活动能力和范围的 土壤节肢动物, 从而提高数据的完整性和可靠性 (黄杰灵等, 2013)。陷阱法的捕获效率还受到生境类 型、作物种植密度的影响(MacGavin, 1997; Zou et al, 2012)。入选的方法和类群基本都能满足响应敏感性 的要求, 也就是其个体数在有机管理条件下高于常 规管理, 低干扰强度的生境高于高干扰的生境。这 和以往的研究一致, 有机管理由于使用化肥农药少 并采用对生物多样性更为友好的措施, 因此具有更 高的生物多样性。高强度的人为干扰, 除化肥农药 施用外, 还包括除草、翻耕等人为管理措施, 都不
利于维持较高的生物多样性。所有的取样方法和类 群在大棚菜地的捕获效率都最低, 主要是由于其封 闭的环境和强的集约化程度。因此, 将不同方法和 不同生物类群, 特别是生活习性差异大、相互关系 少、进化关系远的类群进行组合会有更好的指示效 果(Duan et al, 2016a)。不同方法和指示生物类群的 组合也可以减少由一种方法或类群带来的偏差甚 至错误的结果。地表陷阱法可以捕获地表捕食性为 主的步甲和蜘蛛, 而挂盆法对于传粉节肢动物, 特 别是蜂类具有较好的效果, 且两种方法的取样仪器 可以同时布置。因此, 综合考虑捕获效率、经济成 本、响应敏感性、类群功能价值、操作难易, 地陷 法捕获步甲或/和蜘蛛以及挂盆法调查蜂类的组合 是基于本研究的最佳组合。

致谢：感谢宁波天胜农牧“四不用”农场职工装辰 光、俞婉君、陈良才、梁东生的田间协助。感谢古 林镇共任村经济合作社吴红峰社长对调查的支持 和帮助。

\section{参考文献}

Altieri MA (1999) The ecological role of biodiversity in agroecosystems. Agriculture, Ecosystems \& Environment, 74, 19-31.

Belfrage K, Bjrklund J, Salomonsson L, Liang H (2005) The effects of farm size and organic farming on diversity of birds, pollinators, and plants in a Swedish landscape. AMBIO-A Journal of the Human Environment, 34, 576-582, 643. (in Chinese) [Belfrage K, Bjrklund J, Salomonsson L, 梁虹 (2005) 农场规模和有机耕作对瑞 典一个景观区域内鸟类、传粉者和植物多样性的影响. AMBIO-人类环境杂志, 34, 576-582, 643.]

Benton TG, Vickery JA, Wilson JD (2003) Farmland biodiversity: Is habitat heterogeneity the key? Trends in Ecology \& Evolution, 18, 182-188.

Bertrand C, Baudry J, Burel F (2016) Seasonal variation in the effect of landscape structure on ground-dwelling arthropods and biological control potential. Basic and Applied Ecology, 17, 678-687.

Butler SJ, Vickery JA, Norris K (2007) Farmland biodiversity and the footprint of agriculture. Science, 315, 381-384.

Cai BH, Cai XM, Huang FS (2017) Insect Taxonomy (Revised Edition). Chemical Industry Press, Beijing. (in Chinese) [蔡 邦华, 蔡晓明, 黄复生 (2017) 昆虫分类学(修订版). 化 学工业出版社, 北京.]

Concepción ED, Díaz M, Kleijn D, Báldi A, Batáry P, Clough Y, Gabriel D, Herzog F, Holzschuh A, Knop E, Marshall EJP, Tscharntke T, Verhulst J (2012) Interactive effects of 
landscape context constrain the effectiveness of local agri-environmental management. Journal of Applied Ecology, 49, 695-705.

Costanza R, d'Arge R, de Groot R, Farber S, Grasso M, Hannon B, Limburg K, Naeem S, O’Neill RV, Paruelo J, Raskin RG, Sutton P, van den Belt M (1998) The value of the world's ecosystem services and natural capital. Ecological Economics, 25, 3-15.

Dennis $\mathrm{P}$, Bogers $\mathrm{M}$, Bunce $\mathrm{R}$, Herzog $\mathrm{F}$, Jeanneret $\mathrm{P}$, Geijzendorffer I, Jongman R (2012) Biodiversity in organic and low-input farming systems. Handbook for recording key indicators. Wageningen, Alterra, Alterra-Rreport, 2308.

Duan MC, Hu WH, Liu YH, Yu ZR, Li X, Wu PL, Zhang F, Shi HL, Baudry J (2019) The influence of landscape alterations on changes in ground beetle (Carabidae) and spider (Araneae) functional groups between 1995 and 2013 in an urban fringe of China. Science of the Total Environment, 689, 516-525.

Duan MC, Liu YH, Yu ZR, Baudry J, Li LT, Wang CL, Axmacher JC (2016a) Disentangling effects of abiotic factors and biotic interactions on cross-taxon congruence in species turnover patterns of plants, moths and beetles. Scientific Reports, 6, 23511.

Duan MC, Liu YH, Yu ZR, Li LT, Wang CL, Axmacher JC (2016b) Environmental factors acting at multiple scales determine assemblages of insects and plants in agricultural mountain landscapes of Northern China. Agriculture, Ecosystems \& Environment, 224, 86-94.

Fahrig L, Baudry J, Brotons L, Burel FG, Crist TO, Fuller RJ, Sirami C, Siriwardena GM, Martin JL (2011) Functional landscape heterogeneity and animal biodiversity in agricultural landscapes. Ecology Letters, 14, 101-112.

Fahrig L, Girard J, Duro D, Pasher J, Smith A, Javorek S, King D, Lindsay KF, Mitchell S, Tischendorf L (2015) Farmlands with smaller crop fields have higher within-field biodiversity. Agriculture, Ecosystems \& Environment, 200, 219-234.

Huang JL, Hu G, Yuan JF, Luo YY (2013) A comparison of pitfall trapping and the Winkler method for investigating soil arthropod diversity: A case study on the closed habitats of Land-bridge Islands. Chinese Journal of Applied Entomology, 50, 1679 1691. (in Chinese with English abstract) [黄杰灵, 胡广, 袁金凤, 罗媛媛 (2013) 陷阱法 和Winkler法调查土壤节肢动物多样性比较: 以千岛湖岛 屿封闭生境研究为例. 应用昆虫学报, 50, 1679-1691.]

Kleijn D, Kohler F, Báldi A, Batáry P, Concepcion ED, Clough Y, Díaz M, Gabriel D, Holzschuh A, Knop E, Kovács A, Marshall EJP, Tscharntke T, Verhulst J (2009) On the relationship between farmland biodiversity and land-use intensity in Europe. Proceedings of the Royal Society B, 276, 903-909.

Klein AM, Steffan-Dewenter I, Tscharntke T (2003) Fruit set of highland coffee increases with the diversity of pollinating bees. Proceedings of the Royal Society of London Series B-Biological Sciences, 270, 955-961.

Li ZY, Altieri MA, Zhu YY (2009) Biodiversity and Integrated Pest Management. Science Press, Beijing. (in Chinese) [李 正跃, Altier MA, 朱有勇 (2009) 生物多样性与害虫综合 治理. 科学出版社, 北京.]

Liu XD (2013) Sampling techniques of insects in the field. Chinese Journal of Applied Entomology, 50, 863-867. (in Chinese with English abstract) [刘向东 (2013) 田间昆虫 的取样调查技术. 应用昆虫学报, 50, 863-867.]

Liu YF, Gu DX, Zhang GR (2002) An investigation of species of predatory arthropods in paddy ecosystems. Natural Enemies of Insects, 24, 145-153. (in Chinese with English abstract) [刘雨芳, 古德祥, 张古忍 (2002) 稻田生态系统 中捕食性天敌节肢动物种类调查分析. 昆虫天敌, 24, 145-153.]

Liu YF, Zhang GR, Gu DX (1999) Study on arthropod communities in paddy fields with modified fluke. Plant Protection, 25(6), 39-40. (in Chinese) [ 刘雨芳, 张古忍, 古 德祥 (1999) 利用改装的吸虫器研究稻田节肢动物群落. 植物保护, 25(6), 39-40.]

MacGavin GC (1997) Expedition Field Techniques: Insects and Other Terrestrial Arthropods. Royal Geographical Society, London.

Pimentel D, Stachow U, Takacs DA, Brubaker HW, Dumas AR, Meaney JJ, O’Neil JAS, Onsi DE, Corzilius DB (1992) Conserving biological diversity in agricultural/forestry systems: Most biological diversity exists in human-managed ecosystems. BioScience, 42, 354-362.

Rainio J, Niemelä J (2003) Ground beetles (Coleoptera: Carabidae) as bioindicators. Biodiversity \& Conservation, 12, 487-506.

Shi B, Yao FL, Chen SB, You MS (2011) An improved pitfall trap for better sampling of spiders in paddy fields. Chinese Journal of Applied Entomology, 48, 782-786. (in Chinese with English abstract) [施波，姚凤銮，陈少波，尤民生 (2011) 陷阱法的改进及其在稻田蜘蛛取样中的应用. 应 用昆虫学报, 48, 782-786.]

Sun YF, Chen BX, Jin B, Zhu SH, Zhang SB, Zhang HB, Li YK, Liu YH, Duan MC (2019) Effects of organic management on the diversity of $\alpha, \beta$ and $\gamma$ of herbaceous plants in different agricultural habitats. Chinese Journal of Eco-Agriculture, 27, 1617-1625. (in Chinese with English abstract) [孙玉芳, 陈宝雄，金涁，朱升海，张松柏，张宏 斌，李圭奎，刘云慧，段美春 (2019) 有机管理对不同农 田生境草本植物 $\alpha, \beta$ 和 $\gamma$ 多样性的影响. 中国生态农业学 报(中英文), 27, 1617-1625.]

Tscharntke T, Klein AM, Kruess A, Steffan-Dewenter I, Thies C (2005) Landscape perspectives on agricultural intensification and biodiversity-ecosystem service management. Ecology Letters, 8, 857-874.

Wang HQ, Yan HM, Yang HM (1996) Studies on the ecology of spiders in paddy fields and utilization of spiders for 
biological control in China. Scientia Agricultura Sinica, 29(5), 68-75. (in Chinese with English abstract) [王洪全, 颜亨梅, 杨海明 (1996) 中国稻田蜘蛛生态与利用研究. 中国农业科学, 29(5), 68-75.]

Wang R, Ding SY, Lu XL, Song B (2017) Effects of landscape simplification on pollinator diversity in agricultural areas near the lower reaches of the Yellow River: A case study. Acta Ecologica Sinica, 37, 2225-2236. (in Chinese with English abstract) [王润, 丁圣彦, 卢训令, 宋博 (2017) 黄 河中下游农业景观中景观简化对传粉昆虫多样性的影响 一以巩义市为例. 生态学报, 37, 2225-2236.]

Wang Y, Chen J, Xiao DH, Ma FG, Hua HX (2016) Assessing the efficacy of different sampling methods for arthropods in rice field. Journal of Environmental Entomology, 38, 1090-1098. (in Chinese with English abstract) [王宇, 陈杰, 肖敦皇, 马富岗, 华红霞 (2016) 不同取样方式在稻田节 肢动物采集中的效率评估. 环境昆虫学报, 38, 1090-1098.]

Wu JC, Guo YJ, Shu ZL, Yang JS (1993) Comparison of different sampling methods for arthropod communities in rice fields. Entomological Knowledge, 30, 182-183. (in Chinese) [ 吴进才, 郭玉杰, 束兆林, 杨金生 (1993) 稻田 节肢动物群落不同取样方法的比较. 昆虫知识, 30, 182-183.]

Wu PL, Song X, Xia BH, Xu HL, Liu YH (2018) Temporal-spatial dynamics of wild bee diversity in agricultural landscapes in Changping District, Beijing. Chinese Journal of Eco-Agriculture, 26, 357-366. (in Chinese with English abstract) [伍盘龙, 宋潚, 夏博辉, 徐 环李, 刘云慧 (2018) 北京昌平区农业景观野生蜂多样 性的时空动态分布. 中国生态农业学报, 26, 357-366.]

Yin WY (1992) Subtropical Soil Animals of China. Science Press, Beijing. (in Chinese) [尹文英 (1992) 中国亚热带土 壤动物. 科学出版社, 北京.]

Yin WY (1998) Chinese Soil Fauna Retrieval Map. Science Press, Beijing. (in Chinese) [尹文英 (1998) 中国土壤动物
检索图鉴. 科学出版社, 北京.]

You MS, Liu YF, Hou YM (2004) Biodiversity and integrated pest management in agroecosystems. Acta Ecologica Sinica, 24, 117-122. (in Chinese with English abstract) [ 尤民生, 刘雨芳, 侯有明 (2004) 农田生物多样性与害虫综合治 理. 生态学报, 24, 117-122.]

Zhang JE (1999) Agricultural biodiversity and its protection in China. Journal of Ecology and Rural Environment, 15(2), 37-41. (in Chinese) [章家恩 (1999) 中国农业生物多样性 及其保护. 农村生态环境, 15(2), 37-41.]

Zhang KH, Zhong L (1992) Accuracy comparison of several pest investigation methods in rice field. China Plant Protection, 12(3), 45-46. (in Chinese) [章康华, 钟玲 (1992) 水稻田几种害虫调查方法的准确性比较. 中国植 保导刊, 12(3), 45-46.]

Zheng LY, Gui H (1999) Insect Classification. Nanjing Normal University Press, Nanjing. (in Chinese) [郑乐怡, 归鸿 (1999) 昆虫分类(上、下). 南京师范大学出版社, 南京.]

Zhou HZ, Yu XD, Luo TH, Li XY, Wang FY, Li DE, Zhou YLZ, Zhao CY (2014) Collecting methods and sampling techniques of ground dwelling and predating carabids and staphylinids beetles. Chinese Journal of Applied Entomology, 51, 1367-1375. (in Chinese with English abstract) [周红章, 于晓东, 罗天宏, 李晓燕, 王凤艳, 李 德娥, 周毓灵子, 赵彩云 (2014) 土壤步甲和隐翅虫的采 集与田间调查取样技术. 应用昆虫学报, 51, 1367-1375.]

Zou Y, Feng JC, Xue DY, Sang WG, Axmacher JC (2012) A comparison of terrestrial arthropod sampling methods. Journal of Resources and Ecology, 3, 174-182.

Zou Y, van Telgen MD, Chen JH, Xiao HJ, de Kraker J, Bianchi FJ, van der Werf W (2016) Modification and application of a leaf blower-vac for field sampling of arthropods. Journal of Visualized Experiments, 114, e54655.

(责任编委：傅声雷 责任编辑：时意专)

\section{附录 Supplementary Material}

\section{附录1 吸虫器法在露天农田和稻田的取样效率与其他方法的比较}

Appendix 1 Difference of the sampling efficiency between vacuum-suction method and other methods in open field and rice field http://www.biodiversity-science.net/fileup/PDF/2020034-1.pdf

附录2 生物多样性指标在不同管理措施和生境下的差异显著性

Appendix 2 The statistical differences of biodiversity indicators under different management measures and habitats http://www.biodiversity-science.net/fileup/PDF/2020034-2.pdf 
段美春, 覃如霞, 张宏斌, 陈宝雄, 金涁, 张松泊, 任少鹏, 金树权, 朱升海, 华家宁, 刘云慧, 宇振荣 (2021) 农田节肢动物不同取样方法的综合比较. 生 物多样性, 29 (4): 477-487.

http://www.biodiversity-science.net/CN/10.17520/biods.2020034

附录 1 吸虫器法在露天农田和稻田的取样效率和其他方法的比较(单位: 个体数)

Appendix 1 Difference of the sampling efficiency between vacuum-suction method in open field and rice field and other methods (Unit: individuals)

\begin{tabular}{|c|c|c|c|c|c|}
\hline & $\begin{array}{l}\text { 挂 盆法 Coloured } \\
\text { pan traps }\end{array}$ & $\begin{array}{l}\text { 目测法 Visual } \\
\text { counting }\end{array}$ & $\begin{array}{l}\text { 地陷法 Surface } \\
\text { trap cup method }\end{array}$ & $\begin{array}{l}\text { 扫网 法 Sweeping } \\
\text { method }\end{array}$ & $\begin{array}{c}\text { 吸虫器 Vacuum- } \\
\text { suction method }\end{array}$ \\
\hline 鞘翅目 Coleoptera & 313 & 31 & 16 & 62 & 36 \\
\hline 蜘蛛目 Araneae & 269 & 71 & 315 & 81 & 155 \\
\hline 鳞翅目 Lepidoptera & 114 & 6 & 2 & 10 & 31 \\
\hline 膜翅目 Hymenoptera & 238 & 76 & 102 & 24 & 11 \\
\hline 双翅目 Diptera & 515 & 32 & 49 & 62 & 67 \\
\hline 直翅目 Orthoptera, & 27 & 27 & 67 & 59 & 76 \\
\hline 半翅目 Hemiptera & 106 & 491 & 1 & 255 & 52 \\
\hline 漂虫 Ladybug & 20 & 2 & 0 & 6 & 7 \\
\hline 金龟子 Scarab & 52 & 0 & 0 & 0 & 0 \\
\hline 步甲 Carabidae & 21 & 0 & 10 & 0 & 4 \\
\hline 蜂类 Bee & 180 & 0 & 12 & 23 & 4 \\
\hline 总个体数 Total & 2,495 & 1,145 & 563 & 564 & 430 \\
\hline
\end{tabular}


段美春, 覃如霞, 张宏斌, 陈宝雄, 金彬, 张松泊, 任少鹏, 金树权, 朱升海, 华家宁, 刘云慧, 宇振荣 (2021) 农田节肢动物不同取样方法的综合比较. 生 物多样性, 29 (4): 477-487.

http://www.biodiversity-science.net/CN/10.17520/biods.2020034

附录 2 生物多样性指标在不同管理措施和生境下的差异显著性

Appendix 2 The statistical differences of biodiversity indicators under different management measures and habitats

\begin{tabular}{|c|c|c|c|c|c|c|c|c|c|c|}
\hline $\begin{array}{l}\text { 方法 } \\
\text { Method }\end{array}$ & $\begin{array}{l}\text { 类群或指 } \\
\text { 标 Taxon } \\
\text { or } \\
\text { indicator }\end{array}$ & $\begin{array}{l}\text { 标本总数 } \\
\text { Total } \\
\text { number of } \\
\text { specimens }\end{array}$ & $\begin{array}{l}\text { 有机和常规管 } \\
\text { 理区是否显 } \\
\text { Are organic and } \\
\text { conventional } \\
\text { management } \\
\text { areas significant }\end{array}$ & $\begin{array}{l}\text { 哪种管理 } \\
\text { 区显著性 } \\
\text { 高 Which } \\
\text { managemen } \\
\mathrm{t} \text { area is } \\
\text { significant } \\
\end{array}$ & $\begin{array}{l}\text { 生境间是 } \\
\text { 否显著 } \\
\text { Significant } \\
\text { between } \\
\text { habitats }\end{array}$ & $\begin{array}{l}\text { 大棚蔬菜 } \\
\text { Greenhouse } \\
\text { vegetable } \\
\text { plot }\end{array}$ & $\begin{array}{l}\text { 果园 } \\
\text { Orch } \\
\text { ard }\end{array}$ & $\begin{array}{l}\text { 露天农 } \\
\text { 田 } \\
\text { Open } \\
\text { farmland }\end{array}$ & $\begin{array}{l}\text { 农田边界 } \\
\text { Farmland } \\
\text { boundary }\end{array}$ & $\begin{array}{l}\text { 水稻田 } \\
\text { 埂 Rice } \\
\text { field } \\
\text { ridge }\end{array}$ \\
\hline \multirow[t]{2}{*}{ 挂盆法 CT } & 总个体数 & 23,473 & 显著 & 有机 & 显著 & $\mathrm{c}$ & $\mathrm{bc}$ & $\mathrm{b}$ & $\mathrm{b}$ & $\mathrm{a}$ \\
\hline & Total & & Significant & Organic & Significant & & & & & \\
\hline \multirow[t]{2}{*}{ 地陷法 ST } & 总个体数 & 13,796 & 显著 & 有机 & 否 No & - & - & - & - & - \\
\hline & Total & & Significant & Organic & & & & & & \\
\hline \multirow{2}{*}{ 扫网法 SN } & 总个体数 & 7,091 & 显著 & 常规 & 显著 & $\mathrm{b}$ & $\mathrm{a}$ & $\mathrm{b}$ & $\mathrm{b}$ & $\mathrm{b}$ \\
\hline & Total & & Significant & $\begin{array}{l}\text { Convention } \\
\text { al }\end{array}$ & Significant & & & & & \\
\hline \multirow[t]{2}{*}{ 挂盆法 CT } & 直翅目 & 296 & 显著 & 有机 & 显著 & $\mathrm{b}$ & $\mathrm{a}$ & $\mathrm{a}$ & $\mathrm{a}$ & $\mathrm{a}$ \\
\hline & Orthoptera & & Significant & Organic & Significant & & & & & \\
\hline \multirow{2}{*}{ 地陷法 ST } & 直翅目 & 1,462 & 显著 & 有机 & 显著 & $\mathrm{a}$ & $\mathrm{a}$ & a & $\mathrm{a}$ & $\mathrm{b}$ \\
\hline & Orthoptera & & Significant & Organic & Significant & & & & & \\
\hline \multirow[t]{2}{*}{ 扫网法 SN } & 直翅目 & 392 & 显著 & 有机 & 显著 & $\mathrm{c}$ & $\mathrm{a}$ & $a b$ & $\mathrm{ab}$ & $\mathrm{bc}$ \\
\hline & Orthoptera & & Significant & Organic & Significant & & & & & \\
\hline \multirow[t]{2}{*}{ 挂盆法 CT } & 蜘蛛数 & 3,495 & 否 No & - & 否 No & - & - & - & - & - \\
\hline & Spider & & & & & & & & & \\
\hline \multirow[t]{2}{*}{ 地陷法 ST } & 蜘蛛数 & 4,214 & 显著 & 有机 & 显著 & $\mathrm{bc}$ & a & $\mathrm{ab}$ & $\mathrm{ab}$ & $\mathrm{bc}$ \\
\hline & Spider & & Significant & Organic & Significant & & & & & \\
\hline \multirow[t]{2}{*}{ 扫网法 SN } & 蜘蛛数 & 800 & 显著 & 常规 & 显著 & $\mathrm{b}$ & a & $\mathrm{ab}$ & $\mathrm{ab}$ & $\mathrm{b}$ \\
\hline & Spider & & Significant & $\begin{array}{l}\text { Convention } \\
\text { al }\end{array}$ & Significant & & & & & \\
\hline 目测法 VC & $\begin{array}{l}\text { 蜘蛛数 } \\
\text { Spider }\end{array}$ & 518 & 否 No & - & 否 No & - & - & - & - & - \\
\hline \multirow[t]{2}{*}{ 挂盆法 CT } & 双翅目 & 8,455 & 否 No & - & 显著 & $\mathrm{c}$ & $\mathrm{b}$ & $\mathrm{b}$ & $\mathrm{bc}$ & a \\
\hline & Diptera & & & & Significant & & & & & \\
\hline 地陷法 ST & $\begin{array}{l}\text { 双翅目 } \\
\text { Diptera }\end{array}$ & 772 & 否 No & - & 否 No & - & - & - & - & - \\
\hline 扫网法 SN & $\begin{array}{l}\text { 双翅目 } \\
\text { Diptera }\end{array}$ & 821 & 否 No & - & 否 No & - & - & - & - & - \\
\hline 挂盆法 CT & $\begin{array}{l}\text { 鞘翅目 } \\
\text { Coleoptera }\end{array}$ & 4,057 & 是 Yes & $\begin{array}{l}\text { 有机 } \\
\text { Organic }\end{array}$ & 否 No & - & - & - & - & - \\
\hline 地陷法 ST & $\begin{array}{l}\text { 鞘翅目 } \\
\text { Coleoptera }\end{array}$ & 3,076 & $\begin{array}{l}\text { 显著 } \\
\text { Significant }\end{array}$ & $\begin{array}{l}\text { 有机 } \\
\text { Organic }\end{array}$ & 否 No & - & - & - & - & - \\
\hline 扫网法 SN & $\begin{array}{l}\text { 鞘翅目 } \\
\text { Coleoptera }\end{array}$ & 556 & $\begin{array}{l}\text { 显著 } \\
\text { Significant }\end{array}$ & $\begin{array}{l}\text { 有机 } \\
\text { Organic }\end{array}$ & $\begin{array}{l}\text { 显著 } \\
\text { Significant }\end{array}$ & $a b$ & $a b$ & $a b$ & $\mathrm{a}$ & $\mathrm{b}$ \\
\hline \multirow[t]{2}{*}{ 挂盆法 CT } & 漂虫数 & 397 & 显著 & 有机 & 显著 & $\mathrm{b}$ & $\mathrm{a}$ & $\mathrm{a}$ & $\mathrm{a}$ & $\mathrm{b}$ \\
\hline & Ladybug & & Significant & Organic & Significant & & & & & \\
\hline \multirow[t]{2}{*}{ 扫网法 SN } & 漂虫数 & 120 & 显著 & 有机 & 显著 & $\mathrm{b}$ & $\mathrm{a}$ & $\mathrm{a}$ & $\mathrm{a}$ & $\mathrm{b}$ \\
\hline & Ladybug & & Significant & Organic & Significant & & & & & \\
\hline
\end{tabular}


段美春, 覃如霞, 张宏斌, 陈宝雄, 金涁, 张松泊, 任少鹏, 金树权, 朱升海, 华家宁, 刘云慧, 宇振荣 (2021) 农田节肢动物不同取样方法的综合比较. 生 物多样性, 29 (4): 477-487.

http://www.biodiversity-science.net/CN/10.17520/biods.2020034

\begin{tabular}{|c|c|c|c|c|c|c|c|c|c|c|}
\hline $\begin{array}{l}\text { 方法 } \\
\text { Method }\end{array}$ & $\begin{array}{l}\text { 类群或指 } \\
\text { 标 Taxon } \\
\text { or } \\
\text { indicator }\end{array}$ & $\begin{array}{l}\text { 标本总数 } \\
\text { Total } \\
\text { number of } \\
\text { specimens }\end{array}$ & $\begin{array}{l}\text { 有机和常规管 } \\
\text { 理区是否显 } \\
\text { Are organic and } \\
\text { conventional } \\
\text { management } \\
\text { areas significant }\end{array}$ & $\begin{array}{l}\text { 哪种管理 } \\
\text { 区显著性 } \\
\text { 高 Which } \\
\text { managemen } \\
\mathrm{t} \text { area is } \\
\text { significant } \\
\end{array}$ & $\begin{array}{l}\text { 生境间是 } \\
\text { 否显著 } \\
\text { Significant } \\
\text { between } \\
\text { habitats }\end{array}$ & $\begin{array}{l}\text { 大棚蔬菜 } \\
\text { Greenhouse } \\
\text { vegetable } \\
\text { plot }\end{array}$ & $\begin{array}{l}\text { 果园 } \\
\text { Orch } \\
\text { ard }\end{array}$ & $\begin{array}{l}\text { 露天农 } \\
\text { 田 } \\
\text { Open } \\
\text { farmland }\end{array}$ & $\begin{array}{l}\text { 农田边界 } \\
\text { Farmland } \\
\text { boundary }\end{array}$ & $\begin{array}{l}\text { 水稻田 } \\
\text { 埂 Rice } \\
\text { field } \\
\text { ridge }\end{array}$ \\
\hline \multirow[t]{2}{*}{ 挂盆法 CT } & 膜翅目 & 4,094 & 显著 & 有机 & 显著 & $\mathrm{b}$ & $\mathrm{b}$ & $\mathrm{a}$ & $\mathrm{a}$ & $\mathrm{c}$ \\
\hline & $\begin{array}{l}\text { Hymenopt } \\
\text { era }\end{array}$ & & Significant & Organic & Significant & & & & & \\
\hline 地陷法 ST & $\begin{array}{l}\text { 膜翅目 } \\
\text { Hymenopt } \\
\text { era }\end{array}$ & 3,023 & 否 No & - & 否 No & - & - & - & - & - \\
\hline \multirow{2}{*}{ 挂盆法 CT } & 蜂类数 & 2,387 & 显著 & 有机 & 显著 & $\mathrm{b}$ & $\mathrm{a}$ & $\mathrm{a}$ & $\mathrm{a}$ & $\mathrm{a}$ \\
\hline & Bee & & Significant & Organic & Significant & & & & & \\
\hline \multirow[t]{2}{*}{ 地陷法 ST } & 蜂类数 & 96 & 显著 & 有机 & 显著 & $\mathrm{b}$ & $a b$ & a & a & a \\
\hline & Bee & & Significant & Organic & Significant & & & & & \\
\hline \multirow[t]{2}{*}{ 扫网法 SN } & 蜂类数 & 63 & 否 No & - & 显著 & $\mathrm{b}$ & $\mathrm{b}$ & $\mathrm{a}$ & $\mathrm{b}$ & $\mathrm{b}$ \\
\hline & Bee & & & & Significant & & & & & \\
\hline \multirow[t]{2}{*}{ 挂盆法 CT } & 鳞翅目 & 984 & 显著 & 有机 & 否 No & - & - & - & - & - \\
\hline & $\begin{array}{l}\text { Lepidopter } \\
\text { a }\end{array}$ & & Significant & Organic & & & & & & \\
\hline \multirow[t]{2}{*}{ 挂盆法 CT } & 步甲数 & 673 & 显著 & 有机 & 显著 & $\mathrm{b}$ & $\mathrm{a}$ & $\mathrm{a}$ & $\mathrm{a}$ & $\mathrm{a}$ \\
\hline & Carabidae & & Significant & Organic & Significant & & & & & \\
\hline \multirow[t]{2}{*}{ 地陷法 ST } & 步甲数 & 724 & 显著 & 有机 & 显著 & d & c & a & $\mathrm{ab}$ & $\mathrm{bc}$ \\
\hline & Carabidae & & Significant & Organic & Significant & & & & & \\
\hline \multirow[t]{2}{*}{ 地陷法 ST } & 倍足纲 & 249 & 显著 & 有机 & 否 No & - & - & - & - & - \\
\hline & Diplopoda & & Significant & Organic & & & & & & \\
\hline \multirow[t]{2}{*}{ 挂盆法 CT } & 半翅目 & 1,102 & 显著 & 有机 & 显著 & $\mathrm{b}$ & $\mathrm{a}$ & $\mathrm{a}$ & $\mathrm{a}$ & $\mathrm{b}$ \\
\hline & Hemiptera & & Significant & Organic & Significant & & & & & \\
\hline \multirow[t]{2}{*}{ 扫网法 SN } & 半翅目 & 1,285 & 否 No & - & 显著 & $\mathrm{b}$ & a & $\mathrm{a}$ & $\mathrm{a}$ & $\mathrm{a}$ \\
\hline & Hemiptera & & & & Significant & & & & & \\
\hline \multirow[t]{2}{*}{ 挂盆法 CT } & 金龟子数 & 520 & 显著 & 有机 & 显著 & $\mathrm{bc}$ & $\mathrm{b}$ & $\mathrm{a}$ & $\mathrm{a}$ & $\mathrm{c}$ \\
\hline & Scarab & & Significant & Organic & Significant & & & & & \\
\hline
\end{tabular}

a、b、c、d 代表指标在不同生境间差异的显著性水平 $(P<0.05)$, 同一行的单元格如果具有 1 个相同的字母表示差异不显著, a 对应值最高, b, $\mathrm{c}$ 次 之, $\mathrm{d}$ 最低。a, b, c, d represent the significance level of this indicator in different habitats $(P<0.05)$. If the cell of the same row has the different letter, there is significant difference between them. $\mathrm{a}$ is correspond to the maximum value, the next is $\mathrm{b}$ and $\mathrm{c}, \mathrm{d}$ is correspond to the minimum value. CT, coloured pan traps; VC, visual counting; ST, surface trap cup method; SN, sweeping net method. 